\title{
Numerical and Experimental Study of Temperature Distribution in an Air-cooled Refrigerator Freezer
}

\author{
Jingwei Zeng ${ }^{1,}$ a, ${ }^{*}$, Qifeng Zhu ${ }^{1,2}$, Dongdong Xue ${ }^{1}$ and Hongwei Zhang ${ }^{2}$ \\ ${ }^{1}$ Henan Polytechnic University, Jiaozuo 454000, China. \\ ${ }^{2}$ Henan Xinfei Electrical Appliance Co., Xinxiang 453002, China. \\ *, azengjingwei@hpu.edu.cn
}

\begin{abstract}
A numerical model of flow and temperature field in an air-cooled refrigerator freezer was established by CFD method and was validated by experiments. The results show that the simulation temperature is slightly lower than the experimental results; the maximum relative error is $1.89 \%$. The numerical results show that the shelves divided the freezer into three temperature zones, the vortexes were formed in the door boxes and vegatable box, which weaken the convective heat transfer. Rising the air velocity will improve the uniformity of the temperature distribution in the refrigerator. The research provided a reference for optimal design of the freezer in the air-cooled refrigerator.
\end{abstract}

Keywords: Air-cooled refrigerator, temperature distribution, numerical simulation, freezer

\section{Preface}

At present, foreign research of the air-cooled refrigerator focused on interior flow field and temperature distribution of the freezer, DPIV (Digital Particle Image Velocimetry) method and CFD (Computational Fluid Dynamics) numerical simulation method is the most widely used method among them .Kazuhiro FuKuyo and Tai Tanaami et al performed two-dimensional unsteady simulation of single-door air-cooled refrigerator based on the CFD method, and studied the distribution of the internal temperature difference and the cooling rate of the chamber [1]. J.K.Gupta and M.RamGopal et al simulated the temperature field and flow field of the refrigerating chamber and freezing chamber based on the CFD method [2]. DING Guo-Lianget al. analyzed the flow field and temperature field of the refrigerator by finite element method [3]. SHENG Wei et al. used CFD method to study the temperature distribution of a household refrigerator [4]; Chuan-Chao et al calculated the temperature field and velocity field of the refrigerator by the CFD numerical simulation method, and verified the applicability of the numerical calculation model [5].

In this paper, the numerical simulation of flow and heat transfer of the freezer was carried out based on CFD method, which results provided a reference for the uniformity design of temperature distribution of the freezer in the air-cooled refrigerator.

\section{Geometric Model and Boundary Conditions}

\subsection{Geometric Model}

In this paper, the research object is the freezer in an air-cooled refrigerator. The cold air from the evaporator enters the refrigerator air duct system and enters the freezer through 12 inlets, which has strong convection heat transfer with the original air in the freezer. The insulating layer, shelves, door boxes and vetetable box of the freezer are simplified as solid wall with constant thermal conductivity. The simplified model is shown in figure1. Inside the freezer, there are two shelves, one vegetable box and six door boxes. The simplified model is treated as a regular cuboid with a physical dimension of $590 \mathrm{~mm} \times 490 \mathrm{~mm} \times 604 \mathrm{~mm}$, and there are 12 air inlets and an air outlet in its back wall.

\subsection{Governing Equations}

Due to Reynolds number is greater than 2000 in this paper, Several simplified assumptions are made as follows: steady, continuum, turbulence and no slipping flow; incompressible Newtonian 
fluid; negligible radiation and gravitational force; varied and constant thermo-physical properties for fluid, respectively. Based on above assumptions, the governing equations of continuity, momentum

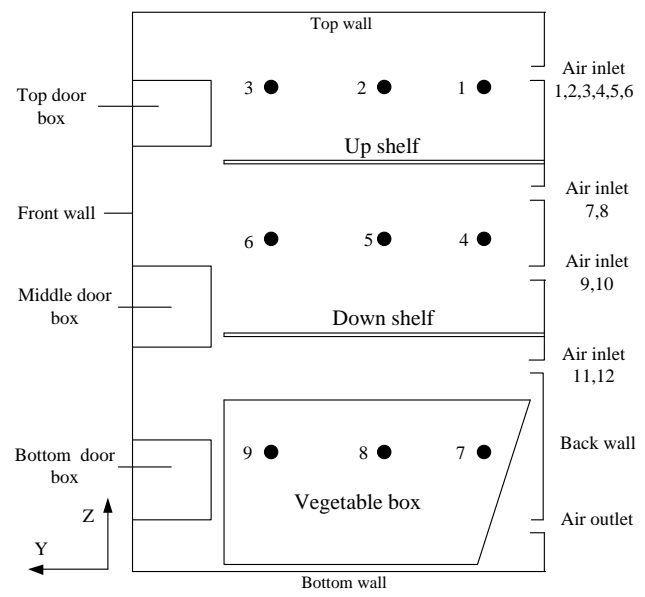

(a) YOZ Directional Projection

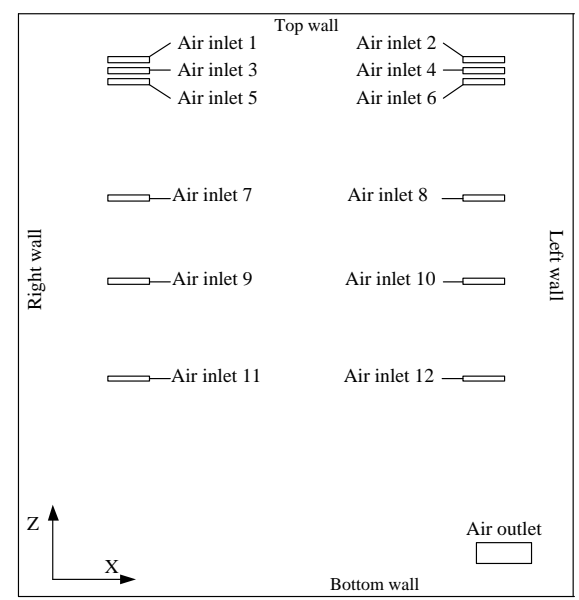

(b) XOZ Directional Projection

Fig. 1 The Simplified Model of the Freezer

and energy equation can be classified as a unified general form:

$$
\begin{gathered}
\nabla \cdot U=0 \\
\rho \frac{D U}{D t}=\nabla \cdot(\mu \nabla U)-\nabla p \\
\rho \frac{D E}{D t}=\nabla \cdot\left(k_{f} \nabla T_{f}\right)-p \nabla \cdot U+\Phi
\end{gathered}
$$

Where: $\nabla$ is Prandtl number, $U$ is velocity vectors, $\rho$ is fluid density, $\mu$ is the fuild viscosity coefficient, $k$ is the fluid thermal conductivity, T is the temperature, $p$ is the fluid pressure, $\Phi$ is the dispersion function,

\subsection{Boundary Conditions}

There are 12 air inlets in the freezer, which are all velocity inlet. the velocity and temperature of the air are shown in table 1 . The outlet of the freezer was set as outflow.

Table 1. Boundary Conditions

\begin{tabular}{cccccc}
\hline Boundary & Temperature(K) & Speed $(\mathrm{m} / \mathrm{s})$ & Boundary & Temperature $(\mathrm{K})$ & $\begin{array}{c}\text { Heat transfer } \\
\text { coefficient } \\
\left(\mathrm{W} /\left(\mathrm{m}^{2} . \mathrm{K}\right)\right)\end{array}$ \\
\hline Inlet 1,3,5 & 263.5 & 1.48 & front wall & 298 & 0.18 \\
Inlet $2,4,6$ & 263.2 & 1.9 & Back wall & 269.5 & 0.45 \\
Inlet 7,8 & 271.7 & 0.86 & Left wall & 298 & 0.5 \\
Inlet 9,10 & $270.5,269.3$ & $1.1,1.25$ & Right wall & 298 & 0.5 \\
Inlet 11 & 270.9 & 1.56 & Top wall & 298 & 0.26 \\
Inlet 12 & 258.9 & 2.95 & Bottom wall & 253 & 0.26 \\
\hline
\end{tabular}

The numerical solution is realized by Fluent 6.3 .26 software. The standard $k-\varepsilon$ turbulence model is adopted as the turbelence model for the fluid flow. The grid mumber is 306328 and the SIMPLEC is chosed as the coupling method of pressure and velocity. The door boxes, shelves and vegatable box are solid materials, which density is $1800 \mathrm{~kg} / \mathrm{m} 3$ and the thermal conductivity is $0.42 \mathrm{~W} /(\mathrm{m} \cdot \mathrm{K})$. The wall in the model is the insulating layer, which density is $50 \mathrm{~kg} / \mathrm{m}^{3}$ and the specific heat capacity is $3000 \mathrm{~W} /(\mathrm{m} \cdot \mathrm{K})$. The heat transfer coefficient and temperature boundary conditions of the insulating layer are also listed in table 1. 


\section{Analysis of Numerical Simulation}

The simulation results in the freezer are shown in figure 2 and figure 3 . Figure 2 is the velocity distribution of the section with $\mathrm{x}=0.145$, figure 3 is the temperature distribution of the section with $\mathrm{x}$ $=0.145$. From the figure 2 , the velocity distribution in the freezer is as follows: the maximum velocity is near the air inlets, where there are jet flows. As the increasing of the distance, the velocity gradually decreases, until reaches the vicinity of the freezer door boxex, the velocity is

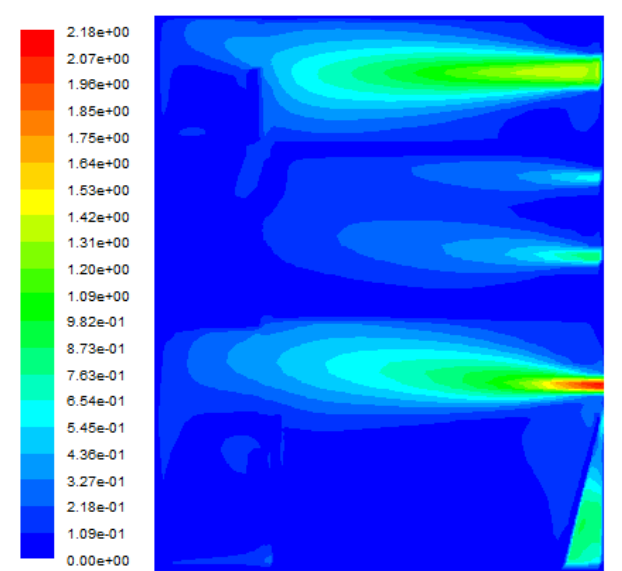

Fig.2 Velocity Distribution $(\mathrm{x}=0.145)$

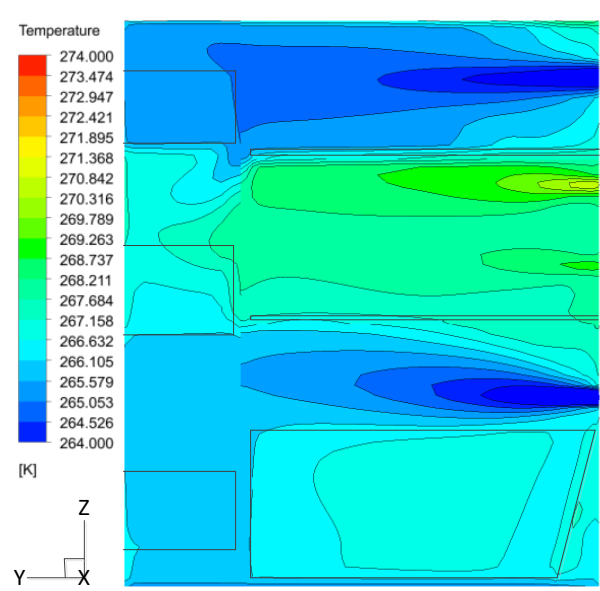

Fig.3 Temperature Distribution $(\mathrm{x}=0.145)$

Very small. The outlet of the lower part of the refrigerator is located between the vegetable box and the back wall, and all the air is discharged from the outlet. the airflow velocity near the outlet is relatively large. Because of the constraint of the solid wall in the door boxes and vegatable box, the airflow velocity is low.

It can be seen from figure 3 that the refrigerator is divided into several temperature zones by shelves, such as top zone, middle zone and bottom zone. The temperature of the middle zone is higher than other zones, because the airinlet temperature in the middle zone is higher than the top zone and the bottom zone. In the bottom zone, the temperature inside the vegetable box is higher because of the poor air flow inside the vegetable box. The air flow passes through the air outlet below the box, so the temperature between the drawer and the bottom wall of the refrigerator is slightly lower than the inside zone of the vegetable box. The airflow througt the bottom inlets reaches the door box, as a result, the temperature of the bottom door box is lower than that inside the vegetable box.

\section{Experimental Comparision and Analysis}

\subsection{Experimental Results}

The experiment is carried out to validate the numerical simulation model by comparing the results of the numerical simulation with the temperature measurement of the test points. The experiment was carried out in a laboratory of constant temperature and humidity. The temperature was set to $298 \mathrm{~K}$ and last for 24 hours. The test condition is empty load operation and the test temperature is the value of steady conditions. The data acquisition system is an Agilent 34970A instrument and the time interval of the data recording is 30 seconds.

In order to reduce the random error, three groups of experiments were carried out to get the average value. In the experiment, 9 temperature testing points were set in the freezer, which were located in the center of each temperature zone. The positions shown in figure1. 
Table 2. Comparison of Numerical and Experiment Results

\begin{tabular}{ccccccc}
\hline $\begin{array}{c}\text { Measuring } \\
\text { point } \\
\text { number }\end{array}$ & $\begin{array}{c}\text { Simulation } \\
\text { value(K) }\end{array}$ & $\begin{array}{c}\text { Experimental } \\
\text { value(K) }\end{array}$ & $\begin{array}{c}\text { Maximum } \\
\text { temperature } \\
\text { difference }\end{array}$ & $\begin{array}{c}\text { Minimum } \\
\text { temperature } \\
\text { difference }\end{array}$ & $\begin{array}{c}\text { Maximum } \\
\text { relative } \\
\text { error }\end{array}$ & $\begin{array}{c}\text { Minimum } \\
\text { relative } \\
\text { error }\end{array}$ \\
\hline 1 & 275.6 & $279.9 \pm 0.5$ & 4.8 & 3.8 & $1.71 \%$ & $1.36 \%$ \\
2 & 275.3 & $280.1 \pm 0.5$ & 5.3 & 4.3 & $1.89 \%$ & $1.54 \%$ \\
3 & 275.3 & $280.1 \pm 0.5$ & 5.3 & 4.3 & $1.89 \%$ & $1.54 \%$ \\
4 & 277.2 & $279.4 \pm 0.5$ & 2.7 & 1.7 & $0.96 \%$ & $0.61 \%$ \\
5 & 277.2 & $279.3 \pm 0.5$ & 2.6 & 1.6 & $0.93 \%$ & $0.57 \%$ \\
6 & 275.6 & $279.1 \pm 0.5$ & 4.0 & 3.0 & $1.43 \%$ & $1.08 \%$ \\
7 & 277.2 & $278.9 \pm 0.5$ & 2.2 & 1.2 & $0.79 \%$ & $0.43 \%$ \\
8 & 277.2 & $278.7 \pm 0.5$ & 2.0 & 1.0 & $0.72 \%$ & $0.36 \%$ \\
9 & 276.6 & $278.7 \pm 0.5$ & 2.6 & 1.6 & $0.93 \%$ & $0.58 \%$ \\
\hline
\end{tabular}

\subsection{Comparative Analysis}

The numerical simulation results are compared with the experimental results, and the comparison are shown in table2. It can be seen from the table 2 that the simulation temperature at the 9 measuring points in the refrigerator is lower than the experimental temperature. The maximum temperature difference is $5.3 \mathrm{~K}$, and the minimum temperature difference is $1.0 \mathrm{~K}$. The maximum relative error of the numerical simulation is $1.89 \%$, and the minimum relative error is $0.36 \%$, which can meet the requirement of engineering application, and it has guiding significance for the design of the air-cooled refrigerator. There are three reasons why the simulated temperature is obviously lower than the experimental temperature. First, the geometric model of refrigerator is simplified for numerical simulation. Second, the air velocity at the inlet is not accurate enough. Third, thermal radiation and the heat leakage of the door seal are ignored.

\section{Conclusion}

(1) The temperature distribution of the freezer compartment depends on the internal flow field, which is effected by the airflow velocity, the air-inlets position and the internal structure of the freezer. The airflow velocity is the maximum influencing factor, so increasing the air velocity will improve the temperature distribution.

(2)The numerical simulation results are lower than the experiments, the maximum relative error of the numerical simulation results is $1.89 \%$ and the minimum relative error is $0.36 \%$, the reason is that the simulation was carried out without considering the heat leakage of the door seal and the influence of the internal heat radiation of the freezer.

(3) There is a large random error in the experiments, so it is necessary to carry out several experiments, and the effect of random error can be reduced by taking the average temperature of all the measuring points.

\section{Acknowledgments}

This work was supported by the Henan Polytechnic University Youth Fund (No.Q2017-2), the Education Basic Research Program of the Henan Provincial Department (No.15A470002), the Coal Mine Safety Production Science and Technology Development Plan in Henan Province(No. HN1561), and the PhD Fund of Henan Polytechnic University (No. B2015-41).

\section{References}

[1]. Fukuyo K, Tanaami T, Ashida H. Thermal uniformity and rapid cooling inside refrigerators [J]. International Journal of Refrigeration, 2003, 26(2):249-255. 
[2]. Gupta J K, Gopal M R, Chakraborty S. Modeling of a domestic frost-free refrigerator [J]. International Journal of Refrigeration, 2007, 30(2):311-322.

[3]. DING Guo-Liang, Oellrich L R. Finite element simulation of air temperature field and flow field in a refrigerator [J]. Journal of Shanghai Jiao Tong University. 1998.32(7):18-22.

[4]. DING Guo-Liang, Oellrich L R. Finite element simulation of air temperature field and flow field in a refrigerator [J]. Journal of Shanghai Jiao Tong University. 1998.32(7):18-22.

[5]. SHENG Wei, LI Fei, SONG Xin-zhou etal. Numerical and Experimental Study of Freezer Compartment of Air-cooled Refrigerator[J].Fluid Machinery. 2015(10):79-83.

[6]. LV Chuan-Chao, CUI Zhen-Ke, WANG Le. Numerical Simulation of Temperature and Velocity Fields in Fresh Food Storage Compartment and Structure Optimization for Refrigerator [J]. Chinese Journal of Refrigeration Technology, 2015,35(5):56-61. 